\title{
Terminal care: evaluation of an advisory domiciliary service at St Christopher's Hospice
}

\author{
C. Murray Parkes \\ M.D., F.R.C.Pysch.
}

Dept of Psychiatry, The London Hospital Medical College, London E1 2AD

In a matched, comparative study the provision of an advisory service to families who were nursing a patient with incurable cancer at home enabled the patient to stay at home longer than he otherwise would and helped the family and primary care team to cope with the added burden which resulted. Families seem to have been well satisfied with the help which was given and there were considerable savings in cost to the health service.

\section{Introduction}

Most people who die from cancer spend some or all of the final weeks of their lives at home (Cartwright, Hockey and Anderson, 1973). This is particularly likely to be the case if they have not suffered severe pain or other distressing symptoms before the terminal period. Nevertheless there is evidence that home-centred care is often associated with distressing symptoms which may not be adequately relieved (Parkes, 1978) and although most people would probably say they would rather die at home than in hospital few of us do so.

In recent years several attempts have been made to improve standards of care for cancer patients at home. Lack and Buckingham (1978) compared 30 patients who had been cared for by a Home Care Service in New Haven, Connecticut, with 35 control patients who received no domiciliary support. Home Care patients reported significantly lower levels of anxiety, depression and hostility than did those without domiciliary support and so did the family member (usually spouse) who was mainly responsible for their care. These differences were most marked in patients of lower socio-economic status who might have been expected to benefit most from a free medical and nursing service. This factor is of particular importance when we realize that the control patients spent $50 \%$ more time in a hospital or other institution than the Home Care patients. Seventy-two per cent. of Home Care patients died at home whereas almost all of the controls died in hospital.
The care to which cancer patients are entitled without payment in Britain is very different. General practitioners are expected to visit the homes of any who are too sick to visit their local surgeries, district nurses nurse such patients in their home and local social workers are normally ready to visit the home if requested to do so. All of these, together with a range of supportive services (home helps, laundry services, etc.) are provided by the National Health Service or local government without payment (save for a few minor exceptions).

General practitioners and district nurses in the vicinity of St Christopher's Hospice in South London have been given the opportunity to receive special training in the care of the patient with incurable cancer and many of them have visited the Hospice or consulted the Hospice staff about particular patients. Consequently the general standard of home care in this area may well be above average.

Nevertheless a Home Care Service was introduced in 1969 to supplement these services, and the effects of this service are evaluated as seen by surviving spouses of patients who received it and are compared with the views of spouses of patients who received the care ordinarily provided in the area.

The service comprises a team of senior nurses who visit patients in their homes and consult with them and their relatives to assess and advise. The team are supported by a physician, a psychiatrist and by the services at St Christopher's Hospice where an out-patient clinic is held each week. The nursing team is essentially advisory and no direct nursing or medical care is provided in the home by it, i.e. it does not replace existing services.

\section{Method of investigation}

In order to assess the effects of the service the cooperation of the Office of Population Statistics and Surveys was obtained to enable the author and his colleagues to locate and visit in their homes surviving 
spouses of patients who had died from cancer in 2 of the boroughs adjacent to St Christopher's Hospice during 1974-76. This was done by obtaining copies of the death registrations of all married men and women under the age of 70 who had died in those boroughs. An explanatory letter was then sent to the surviving spouse and, if no objection was made, a visit was made by an interviewer who asked a series of questions concerning the care which had been provided for the patient during his terminal illness and about the symptoms and feelings experienced. Visits took place about 13 months after the patient's death.

In analysing the data, information obtained from spouses of patients who had died after being visited by St Christopher's Home Care Service was compared with information from matched groups of spouses of cancer patients who had not been visited by the service.

Section I reports assessments of the help received from St Christopher's Home Care team made by 31 surviving spouses who were visited more than once.

Section II compares assessments made by spouses of symptoms and reactions of 51 patients who were visited by the St Christopher's Home Care team with a group of 51 spouses of patients who were cared for at home but were not visited by St Christopher's Home Care team.

Section III focuses on a subsample of 23 matched pairs who died in hospital after spending some time at home and compares attitudes to entering hospital among relatives and patients cared for at home and in St Christopher's Hospice and those cared for elsewhere

\section{Views on home care service}

Surviving spouses were asked to give their opinion of the St Christopher's Home Care Service. Thirtynine out of 70 had been visited only once, 10 had been visited twice and 21 three or more times. One patient could recall nothing about visits. Focusing on the 31 who received 2 or more visits:

In almost all cases the patient and the caregiver had got on 'very well' with the nurse and had talked a great deal to her. In 20 cases, respondents said that the nurse had imparted information about the illness in a sensitive way and none thought that this had been handled insensitively. Practical nursing care was given only twice but on 7 occasions equipment had been provided.

In all cases, the nurse had explained the nature of the illness to the caregiver, and in 6 cases $(19 \%)$ had helped the caregiver to realize that the patient had not long to live. In each of these cases the information had been imparted in a sensitive way and was regarded as 'very helpful'. In all cases the nurse had advised the caregiver how to look after the patient and in nearly all cases (28) had taken an interest in the caregiver's own welfare. Two-thirds $\cong$

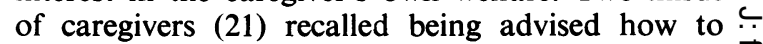
respond to the patient's questions about his or her $\overrightarrow{\vec{F}}$ illness. All were given the telephone number of a $\frac{\vec{\sigma}}{0}$ nurse who could be called if needed but only $9(29 \%)$ had made use of this.

Taken overall, $97 \%$ thought the patient's comfort $\overparen{\mathbb{D}}$ had been improved by the nurse's attentions, $86 \%$ thought the patient's peace of mind improved and $\infty$ in all cases the caregiver's own peace of mind had $\overrightarrow{0}$ been improved.

\section{Assessments of symptoms and reactions matched groups}

Fifty-one patients who had been cared for by St Christopher's Home Care team were matched with 51 who had spent some time at home during the terminal period but had not received any help from St Christopher's. Matching criteria included age ( \pm 10 years), sex, social class ( \pm one SES* category), duration of active treatment ( \pm 5 months) and severity of pain before terminal phase (5-point scale)

Despite this attempt to produce comparable samples there can be little doubt that the group referred to St Christopher's Home Care Servicg were on the whole more 'ill', in the sense that the had more physical problems relating to theis illness than the comparison group. Thus their length of survival from the end of active treatment to death (the 'terminal period') averaged 30.6 weeks compared with 38.7 weeks in the comparison group and they required nursing care of some kind, either at home or in hospital during $88 \%$ of this time whereas the comparison group required nursing during only $57 \%$ of the terminal period. Only 6 St Christopher's patients compared with 17 from the comparison group had any time after the end of active treatment, at home or at work, during which they required no nursing care $\left(\chi^{2} 5.61\right.$ one d.f., $P<0.05)$. Presumably it was the need for care which caused referral to the Hospice in many cases and which accounts for this difference.

One might assume that, since the St Christopher's group were more 'ill' than the comparison group, they would have had to spend more time in hospital but this was not the case. The St Christopher's group spent a mean of 2.6 weeks per patient in hospital during the terminal period whereas the comparison group spent nearly twice this time, 5.6 weeks in hospital. It would seem, therefore, that the Home Care Service is enabling cancer patients to stay at home for a longer period than they otherwise would have done. This conclusion is supported by statistics from the Hospice's annual statistical reports

\footnotetext{
* Socio-economic status.
} 
which show a drop in the mean length of stay on the wards from 34 days in 1968 before the Home Care Service was introduced, to 22 days during 1974, by which time the Home Care Service was fully established. There is a negative correlation $(r=-0.88)$ between the mean length of stay on the wards and the number of families visited by home care staff during the period 1968-76.

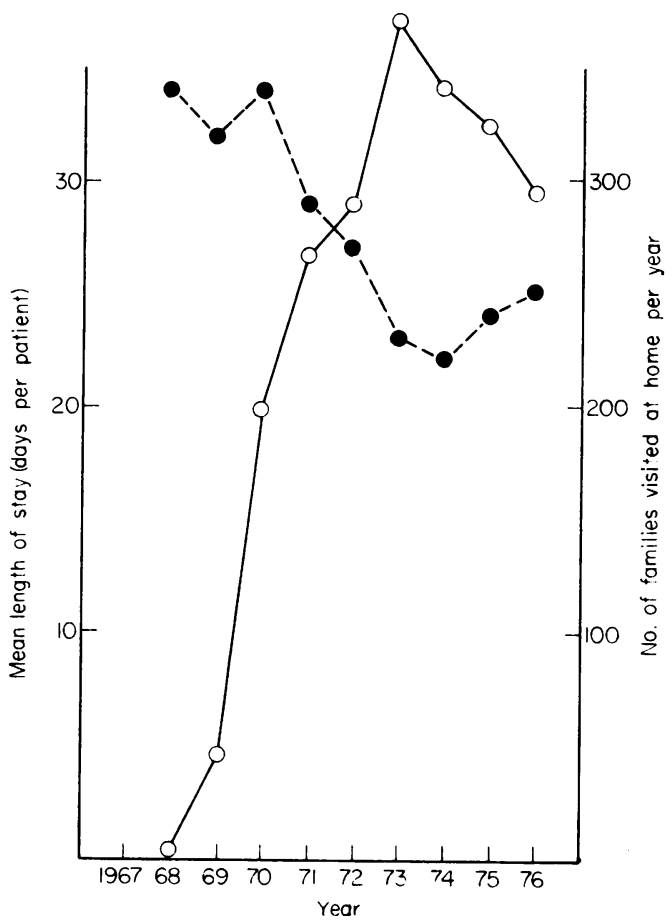

Fig. 1. Home care and length of in-patient care, St Christopher's Hospice 1968-1976. - - Mean length of stay; $\bigcirc-O$ number of families visited at home per year.

But the tendency for St Christopher's patients to spend less time in hospital than the comparison group is not associated with a greater tendency to die at home. In fact 20 patients in the comparison group died at home $(39 \%)$ compared with only 14 $(27 \%)$ of the St Christopher's group (not significant).

The effect of the longer stay at home is, as might be expected, a greater burden of care on the family and the primary care team. Thus, although families were able to provide light nursing care by day for similar periods to the 2 groups the comparison group rarely managed to provide nursing care at night and never provided heavy nursing (defined as nursing care for which 2 persons were needed), whereas the St Christopher's group provided a mean of 0.9 weeks of heavy and 0.42 weeks of night nursing. Presumably, when the illness of the comparison group had progressed to the point where night care was required hospital admission was arranged.

Despite the care which was provided to both groups, caregivers reported a surprising amount of unrelieved physical and emotional distress. There were virtually no differences between the number of distressing symptoms perceived as unrelieved by the spouses of patients cared for at home by the St Christopher's group and the comparison group. Thus reports included unsatisfactory relief of pain (11 St Christopher's and 12 other), breathlessness (8 and $16 \chi^{2} 2.88 P<0 \cdot 10$ ), sleeplessness (8 and 10), nausea and/or vomiting ( 8 and 7 ), drowsiness or confusion ( 22 and 18 ), bedsores ( 3 and 3 ), unpleasant odour ( 9 and 5), depression (24 and 27 ) and anxiety or fear (23 and 29).

Nevertheless, about half the patients in both settings were thought to have been 'content or very content' while at home and none was 'very unhappy' or 'suicidal or asking for euthanasia'.

The interviewer's own assessments did not indicate that there were many serious failures to meet nursing needs in either setting. Thus, in 2 cases from the comparson group and none from St Christopher's the interviewer thought there were 'many serious failures' to meet nursing needs and in 14 from St Christopher's and 6 from other settings there were 'occasional and minor failures' to meet nursing needs $\left(\chi^{2} 5 \cdot 6,2\right.$ d.f., $\left.P<0 \cdot 10\right)$.

Patients in the St Christopher's group were said to have been slightly more tense than the comparison group, $35 \%$ and $13 \%$ showed 'slight' or 'greater' tension $\left(\chi^{2} 5.08\right.$, one d.f., $\left.P<0.05\right)$. Neither group showed more than occasional irritability or anger.

Perhaps as a reflection of the extent to which they were forced to rely on others, $90 \%$ of the St Christopher's group were said to have accepted help reluctantly or felt a burden whereas this was the case in only $69 \%$ of the comparison group $\left(\chi^{2} 5 \cdot 53\right.$, one d.f., $P<0.02$ ).

In both settings it was unusual for patients to have talked about their illness in order to consider its implications for themselves or their families $(21 \%$ St Christopher's and $17 \%$ of comparison group, n.s.). Thus, it seems that the tendency to avoid confronting the realities of terminal illness which is a common phenomenon in dying patients was not substantially affected by visits from a home care nurse.

Forty-three per cent. of St Christopher's group and $47 \%$ from the comparison group got little support from the family or friends. In both settings the family caregiver was likely to be seen as strong and physically capable but $51 \%$ of those supported by St Christopher's compared with only $22 \%$ from the comparison group were fearful of responsibility 
for the patient if he should die under their care and a further $8 \%$ (and $0 \%$ ) felt unable to tolerate any unusual strains in their lives at this time $\left(\chi^{2}\right.$ test on an index of situational stress derived from these questions 12.86, 2 d.f., $P<0 \cdot 01$ ). Although both groups recalled experiencing anxiety during the time the patient was at home this was rated as 'great' by nearly one-third (16) of the St Christopher's group and only $8 \%$ (4) of the rest $\left(\chi^{2} 6 \cdot 78\right.$, one d.f., $P<0.01$ ).

Even so there was no greater tendency for the St Christopher's group to worry about the relief of pain or other distressing symptoms. More than one-third $(36 \%)$ were worried that they might be separated from their spouse compared with $8 \%$ of the rest $\left(\chi^{2} 8.65\right.$, one d.f., $\left.P<0.01\right)$ and although both groups reported worrying about their own future this was rather more common among spouses of St Christopher's patients $\left(77 \%\right.$ and $55 \%, \chi^{2} 3 \cdot 84$, one d.f., $P=0.05$ ).

It would seem, from these figures, that since St Christopher's patients were more 'ill' and were kept at home until a later stage of their illness than other home care patients, this placed an added stress on the family. It might also have added to the responsibilities of the GP and the district nurse. This is confirmed by the interviewer's assessments of GP care as 'doubtful' or 'inadequate' in $12 \%$ of $\mathrm{St}$ Christopher's and $4 \%$ of comparison cases (n.s.). Only $22(43 \%)$ of the comparison group were visited by a district nurse compared with $35(69 \%)$ of the St Christopher's group (n.s.).

\section{Hospital admission}

Confining attention to 23 matched pairs who died in hospital.

Sixty-two per cent. of those patients who subsequently died at St Christopher's Hospice had been visited only once by a nurse from the Hospice before admission. In these cases the main functions of the nurse were to make an assessment of the patient's suitability for admission and to prepare patient and family for this event.

Patients who were admitted to die at St Christopher's had expressed a wish to be admitted more often than patients who died elsewhere.

TABLE 1. Patient's attitude to admission

\begin{tabular}{lcc}
\hline Patient thought to have: & $\begin{array}{c}\text { St Christopher's Comparison } \\
\text { group }\end{array}$ & group \\
\hline Wanted admission & 13 & 5 \\
Accepted it reluctantly & 6 & 9 \\
Did not want or understand it & 1 & 7 \\
Refused at first (later relented) & 1 & 0 \\
Not known & 2 & 0 \\
\hline
\end{tabular}

$\chi^{2} 24 \cdot 4 ; 2$ d.f., $P<0.01$.
Respondents were asked to give their retrospective $\frac{3}{8}$ opinion on how they now feel about the admission. $\propto$

Although neither group regretted admission it is $c$ clear that respondents whose spouses were admitted $\overrightarrow{\bar{F}}$ to other hospitals were less positive in their feelings $\overline{0}$ about admission than caregivers of St Christopher's patients.

TABLE 2. Caregiver's current attitude to admission of patient

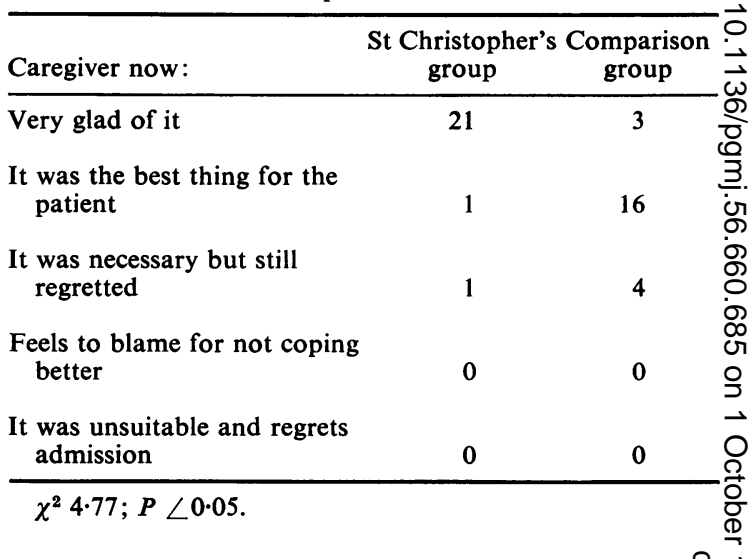

No patients admitted to an 'other hospital' wepect told before admission what sort of a ward they weye. going to and in only 3 cases was the respondert aware that the reasons for admission had been explained to the patient. By contrast, $13(62 \%)$ of those admitted to St Christopher's Hospice were known to have been told what kind of a ward $\stackrel{\varnothing}{\varnothing}$ they were going to and the reasons for admission $\underset{\Rightarrow}{\overrightarrow{2}}$ were known to have been explained. In no case did $\frac{0}{3}$ the respondent think that the patient had been misled either about the type of ward to which he was going or the reasons for admission.

Only one respondent (from St Christopher's Group) was dissatisfied with the length of time the patient had had to wait for a bed. This was, perhaps, 3 . just as well because $48 \%$ from St Christopher's and $\delta$ $13 \%$ from other hospitals died during the first week after admission $\left(\chi^{2} 7 \cdot 58\right.$, one d.f., $\left.P<0.01\right)$.

Twelve from the St Christopher's group felt $\frac{D}{\supset}$ 'definitely' and 10 'probably' that the Hospice nurse had made a difference to the ease with which hospital admission was arranged.

A systematic evaluation of the in-patient service $N$ at St Christopher's Hospice has been published elsewhere (Parkes, 1979 a, b).

\section{Conclusions}

(1) The provision of a Home Care Service on the $\stackrel{\Phi}{\oplus}$ lines provided by St Christopher's Hospice had the effect of enabling patients to stay at home until a. later stage in their illness than would otherwise have $\stackrel{\mathbb{\Phi}}{\circ}$ 
been the case and almost halved the length of time which they spent in hospital. The Hospice is now largely concerned with the short-term admission of patients close to death.

(2) The costs of the Home Care Service ( $£ 87 /$ patient during the period of study) were considerably less than the costs of the in-patient care which they replaced ( $£ 347 /$ patient).

(3) It did not prevent stress on the family or reduce the need for them and the primary care team to provide adequate care. On the contrary, the care given by these people became all the more important and the stresses somewhat greater. Consequently patients were rather more likely to consider themselves a burden and/or to accept help reluctantly.

(4) Because of the selection of patients for referral to the Home Care Service the St Christopher's group seem to have had more nursing needs than the controls. This gave rise to a bias in matching which makes it difficult to know whether or not the provision of the Service resulted in any reduction in the number of unrelieved symptoms or increased the patient's level of contentment. It is quite possible that any improvement in symptom control brought about by the Service simply enabled the patients to stay at home longer than they would otherwise have done until deterioration in their physical state caused fresh symptoms to arise.

(5) There was no evidence that the provision of an advisory service increased the likelihood that patients would talk about their illness or consider its implications for their families; nor did it make it more likely that patients would choose to die at home. It may have eased the patient's passage into hospital as indicated by the reported attitudes of patients to admission.

(6) Surviving family members expressed very positive feelings about the help which they had received from the Service reporting consistent improvement in the patient's and their own peace of mind as a consequence of the nurse's visits.

\section{Acknowledgments}

This study was undertaken with the support of the King Edward's Fund. Thanks are due to Cynthia Coleman, to the Office of Statistical Censuses and Surveys and to the widows and widowers who provided the information on which the study is based.

\section{References}

Cartwright, A., Hockey, L. \& Anderson, J.L. (1973) Life Before Death. Routledge \& Kegan Paul, London.

Lack, S.A. \& Buckingham, R.W. (1978) The First American Hospice: Three Years of Home Care. Hospice Inc., 765 Prospect St., New Haven, Connecticut.

PARKes, C.M. (1978) Home or hospital? Terminal care as seen by surviving spouses. Journal of the Royal College of General Practitioners, 28, 19.

PARKes, C.M. (1979a) Terminal care: evaluation of inpatient service at St Christopher's Hospice. Part I. Views of surviving spouse on effects of the service on the patient. Postgraduate Medical Journal, 55, 517.

PARkeS, C.M. (1979b) Terminal care: evaluation of inpatient service at St Christopher's Hospice. Part II. Selfassessments of effects of the service on surviving spouses. Postgraduate Medical Journal, 55, 523. 